particles passing. The relative performance of the various fabrics remains similar to that found from our earlier tests. We do not regard the Writers' findings as conflicting with our own and would point out that, apart from our cautionary note, we have made no claims for any fabric beyond the conditions of our test.

In answer to the question concerning repeatability we have found that this is generally very good, with woven fabrics performing a little more consistently than non-wovens. The Writers also mention the value of using platen movement against time as a means of comparing the behaviour of fabrics. For the current test series we conducted platen movement and subgrade porewater pressures are being monitored with time in addition to the measurements made in the earlier tests.

Finally, we feel that the work of the Writers reinforces our opinion that much care should be taken with the selection and use of filter fabrics in civil engineering.

\title{
The behaviour of axially and laterally loaded single piles embedded in non-homogeneous soils
}

\author{
BANERJEE, P. K. \& DAVIES, T. G. (1978). Géotechnique 28, No. 3, 309-326
}

\section{F. Randolph, Department of Engineering, University of Cambridge}

Banerjee and Davies describe an approximate analysis for predicting the behaviour of piles embedded in non-homogeneous elastic soils. The method is relatively economic and is capable of application to groups of piles; it is a welcome addition to the computer-based methods of analysis available to the pile designer. In the Paper, results are presented for single piles under axial or lateral loading. The results for axially loaded piles are in reasonable agreement with those obtained by other methods (for example, finite element analysis, or the closed form solution proposed by Randolph and Wroth, 1978). However, it is considered that the charts of influence factors presented for laterally loaded piles (based on piles of length to diameter ratio of 20) may be misleading when applied to piles of higher length to diameter ratios.

As the Authors point out, the majority of piles encountered in practice behave as flexible piles under lateral loading; that is the deformations and bending moments are confined to the upper region of the pile (typically about ten diameters). It thus seems inappropriate to define a stiffness ratio $K_{\mathrm{R}}^{r}$ in terms of the total pile length, which is no longer a relevant parameter for flexible piles. For the same reason, it seems illogical for the pile length to appear in the expressions for the deformation of the pile at the ground surface. For example, two piles of the same cross-section, embedded in a particular soil to different depths (sufficient so that both behave as flexible piles), will have different values of stiffness ratio $K_{\mathrm{R}}$ and thus different values for the influence coefficients $I_{\mathrm{H}}$, etc. However, both piles will deform identically under lateral loading.

A more logical approach would be to non-dimensionalize the pile stiffness ratio by means of the pile width $D$. Thus the stiffness ratio would, in effect, be a ratio of pile modulus to soil modulus (similar to that for axially loaded piles) with the addition of a factor which will depend on the geometry of the pile cross-section. For non-homogeneous soils, the relevant soil modulus is not that at the pile base but an average value over the active length of the pile (i.e. that part which deforms appreciably). Some iteration will be necessary since the active length of pile will itself be a function of the ratio of pile and soil moduli (Randolph, 1977).

Banerjee and Davies state that, for their definition of stiffness ratio $K_{\mathrm{R}}$, the influence coefficients are largely independent of the ratio of pile length to diameter (for constant value of 
Table 1. Comparison of influence factors for stiffness ratio $K_{\mathrm{R}}=10^{-4}(\chi=0, v=0.5)$

\begin{tabular}{|c|c|c|c|c|c|c|c|c|}
\hline Influence coefficients & \multicolumn{2}{|c|}{$I_{\mathrm{H}}$} & \multicolumn{2}{|c|}{$I_{\mathrm{HM}}$} & \multicolumn{2}{|c|}{$I_{\mathrm{MM}}$} & \multicolumn{2}{|c|}{$I_{\mathrm{FH}}$} \\
\hline$L / D$ & 20 & 40 & 20 & 40 & 20 & 40 & 20 & 40 \\
\hline Banerjee and Davies & $70 \cdot 4$ & $72 \cdot 4$ & 270 & 287 & 2084 & 2145 & $27 \cdot 2$ & $28 \cdot 4$ \\
\hline Randolph (equations (1) to (4)) & $61 \cdot 8$ & $77 \cdot 8$ & 281 & 328 & 2167 & 2341 & $25 \cdot 4$ & $31 \cdot 8$ \\
\hline
\end{tabular}

$K_{\mathrm{R}}$ ). This conclusion is not borne out by results from finite element analyses I have conducted. While these results are in good agreement with those quoted by Banerjee and Davies for $L / D=20$, there was found to be greater variation of the influence coefficients $I_{\mathbf{H}}$ and $I_{\mathrm{FH}}$ with the value of $L / D$. From a large number of finite element analyses, the writer (Randolph, 1977) has deduced relationships giving the deflexion and rotation at the ground surface for flexible laterally loaded piles of circular cross-section. From these relationships it is possible to arrive at equivalent expressions for the influence coefficients in terms of $L / D$ and the stiffness ratio $K_{\mathrm{R}}$ as defined by Banerjee and Davies. For a soil where the stiffness is proportional to depth, these are

$$
\begin{aligned}
I_{\mathrm{H}} & =1.06\left[(L / D) / K_{\mathrm{R}}\right]^{1 / 3} \\
I_{\mathrm{HM}} & =0.87\left[(L / D)^{2} / K_{\mathrm{R}}\right]^{1 / 9} \\
I_{\mathrm{MM}} & \left.=1.20[L / D) / K_{\mathrm{R}}{ }^{7}\right]^{1 / 9} \\
I_{\mathrm{FI}} & =0.43\left[(L / D) / K_{\mathrm{R}}\right]^{1 / 3}
\end{aligned}
$$

The relationships compare well with the results in Figs 7 to 10 (Banerjee and Davies) for $L / D=$ $20, x=0$.

However, equations (1) to (4) indicate a significant variation of $I_{\mathrm{H}}$ and $I_{\mathrm{FH}}$ with the value of $L / D$. Thus as $L / D$ increases from 20 to $60, I_{\mathrm{H}}$ and $I_{\mathrm{FH}}$ will increase by a factor of 1.44 . The rcsults quoted by Bancrjec and Davies in Table 1 for $K_{\mathrm{R}}=10^{-4}$ are compared here (also as Table 1) with values calculated from the relationships above. It may be seen that the results from the approximate elastic analysis of Banerjee and Davies are generally within about $10 \%$ of the values deduced from the finite element analyses, but the variation with $L / D$ is more marked in the latter case.

\section{REFERENCES}

Randolph, M. F. (1977). A theoretical study of the performance of piles. PhD thesis. University of Cambridge. Randolph, M. F. \& Wroth, C. P. (1978). An analysis for the deformation of vertically loaded piles. Am. Soc. Civ. Engrs, 104, No. GT12.

\section{A. Wood, Queen Mary College, London}

The Authors are to be congratulated on providing a rational and unified approach to the analysis of piles subjected to both axial and lateral loads. However, with regard to the latter, their assertion that the Poulos (1973) analysis 'broke down completely' for the highly nonhomogeneous case $(\chi=0)$ should, perhaps, be quantified. Results obtained from such an analysis indicate that the horizontal deflexion and rotation at the pile head (for an unrestrained pile) may be overestimated by a factor of two vis-à-vis the 'exact' solution; whereas, the magnitude of the maximum bending moments are predicted to within 20 to $30 \%$ and the 
location of this moment to within $10 \%$. Furthermore, the relative behaviour of different piles is maintained. Bearing in mind the cost effectiveness of such analyses in modelling real soils and the reliability of soils data (note the Authors have used values of $E / C_{u}$ varying from 99 to 175 and in the case of sands, values of $m$ varying from 30 to $70 \mathrm{lbf} / \mathrm{in} .{ }^{2} / \mathrm{in}$.) it is felt that for many applications the use of the approximate method may be justified. This may be especially so in the early stages of a design when the necessary parametric studies are being undertaken. In addition, the incorporation of the effects of local yield of the soil into the approximate model may to a large extent overcome the poor predictive powcr of the elastic homogeneous soil assumption, without incurring a serious cost penalty.

\section{REFERENCE}

Poulos, H. G. (1973). Load deflexion prediction for laterally loaded piles. Aust. Geomech. J. G3, No. 1, 1-8.

\section{Authors' reply}

Mr Randolph questions the use of the pile length as one of the parameters that determines the relative stiffnesses of laterally loaded flexible piles. He defines flexible piles as being those whose physical lengths are greater than their effective (active) lengths. Our definition of flexible piles is rather different; we have defined all non-rigid piles (typically, $K_{\mathrm{R}}<0 \cdot 1$ ) as flexible piles. According to this latter definition, the behaviour of flexible piles may or may not be dependent on their lengths. It should be emphasized that we have attempted to present a comprehensive and unified treatment of the behaviour of laterally loaded piles and have not sought to restrict ourselves to the consideration of flexible piles (Mr Randolph's definition) alone. The piles used in bridge abutments and transmission towers may well lie outside this category.

In some circumstances, where for example an engineer is concerned with a narrow range of pile types, it may be useful to develop design charts from the results given in the Paper. Among the many possibilities, plots of effective lengths in terms of the flexural rigidities of the piles and the soil stiffness (for various degrees of non-homogeneity) are likely to be particularly helpful. Such plots should be viewed with circumspection because, in practice, effective lengths are increased by local yielding of soil at ground level.

The characteristic length employed to non-dimensionalize the relative stiffness ratio $\left(K_{\mathbf{R}}\right)$ is an entirely arbitrary choice. One might adopt the pile diameter, the effective length, an elastic length (Oteo, 1974) or even some fraction of the pile length; it happens that the total pile length is a particularly convenient choice, for the several reasons which are discussed below.

Parenthetically, we are obliged to demonstrate that Mr Randolph's implication that their influence charts for flexible piles lead to anomalous results is incorrect. Following his example, let the first pile (A) be defined as follows: $D=1, L=20, E_{\mathrm{p}}=6520$. Let the second pile (B) be twice as long, i.e. $L=40$, and both piles be embedded in a non-homogeneous soil $(\chi=0)$ in which the rate of increase of modulus with depth $(m)$ is unity. Thus $\left(K_{\mathrm{R}}\right)_{\mathrm{A}}=10^{-4}$ and $\left(K_{\mathrm{R}}\right)_{\mathrm{B}}=3 \cdot 1 \times 10^{-6}$, i.e. both piles are relatively flexible. The corresponding influence factors for $I_{\mathrm{H}}$ are 70.4 (Table 1) and 260 (Fig. 7 of the Paper) respectively. Thus, from equation (5) of the Paper, the lateral pile-head displacements $(u)$ of these piles due to a lateral load $H$ are $0 \cdot 176 H$ and $0 \cdot 163 H$ respectively; i.e. the longer pile is only marginally stiffer.

This difference is reduced further if our quoted variation of the influence factors with the slenderness ratio is taken into account. Thus, for practical purposes, the behaviour of these two piles may be regarded as essentially identical. Therefore, contrary to the impression Mr Randolph gives in his discussion, the theoretical results presented in the Paper are valid for both flexible and rigid piles. 
We believe that the natural choice for a relative stiffness factor for laterally loaded piles must be the one that contains the flexural rigidity of the piles in explicit form $\left(K_{\mathrm{R}}\right.$ conforms to this ideal) and would submit that a simple ratio between the pile and soil moduli, as advocated by $\mathrm{Mr}$ Randolph, is not appropriate for this purpose.

An important advantage of defining the relative stiffness factor $\left(K_{\mathrm{R}}\right)$ in this manner is that the results are, thereby, directly applicable to piles which have non-circular (or annular) crosssections. Although Amir and Rutenberg (1974) have indicated that there exists a significant shape effect between piles of different cross-section, this is not important in practice. They showed that the reactions exerted by an elastic soil due to the deflexion of a square pile may be approximately $20 \%$ greater than those generated by the deflexion of a circular pile. But in practice, the shape effect is insignificant because the soil yields locally near the corners of square piles, whereas the elastic theory predicts the existence of stress concentrations which increases the ground reaction.

Whatever choice of stiffness factor is adopted, we would argue that it is meaningless to refer to a 'relevant soil modulus'. The only relevant parameters are those that define the variation of soil modulus with depth, namely, $E(0)$ and $m$ in the Paper. In practice, the soil stiffness profile is likely to be irregular. In that case a straight line must be fitted to the field data: for laterally loaded flexible piles the greatest weight should be given to the data pertaining to the soil surrounding the upper part of the pile.

The soil modulus at base level $E(L)$ and the degree of non-homegeneity $(\chi)$ can be determined from the characteristic soil parameters, $E(0)$ and $m$, via the equations $E(\mathrm{~L})=E(0)+m L$ and $\chi=E(0) / E(L)$.

It should be emphasized that there is no question of $E(L)$ being a 'relevant' modulus or otherwise. This transformation of parameters facilitates the task of illustrating (Figs 7 to 10 of the Paper) the major influence that the soil stiffness profile has on pile behaviour and, thereby, provides a means of comparing the behaviour of piles cmbedded in homogeneous and non-homogeneous soils.

Finally, we believe that it is generally preferable to plot the characteristics of complex mathematical systems in terms of simple, but physically meaningful, functions of the primary parameters. In this manner, ambiguity is most easily avoided whilst the utmost economy (in the number of plots) may be realized. Thus, in the present case, the physical pile lengths have been adopted throughout in preference to the effective or elastic pile lengths.

$\mathrm{Mr}$ Randolph has proposed some interesting empirical formulae: these formulae correspond to the linear log-log relationships given in the Authors' influence charts for flexible piles. (It is believed that the formula for the influence factor $I_{\mathrm{HM}}$ is incorrect and, possibly, the correct form might be

$$
I_{\mathrm{HM}}=0 \cdot 87\left[(L / D)^{2} /\left(K_{\mathrm{R}}\right)^{5}\right]^{1 / 9}
$$

It is comforting that the results of our analysis generally agrees quite well with the results of an independent finite element analysis. However, the greater variation of the influence factors $I_{\mathrm{H}}$ and $I_{\mathrm{FH}}$ with the slenderness ratio that has been found by $\mathrm{Mr}$ Randolph is perplexing. A statement of the accuracy of these very simple equations would have been welcomed since the comparisons with our results have been carried out using these equations rather than by a direct use of the finite element analysis. There are, of course, particular difficulties in performing finite element analyses of the flexure of slender beams, primarily due to the existence of 'parasitic' shear deformations which necessitate the use of reduced integration techniques. These difficulties are discussed by Kuhlmeyer (1979).

Furthermore, in order to investigate, by a finite element method, the effects of slenderness 
ratio on the behaviour of laterally loaded flexible piles it is necessary to specify very rigorous convergence criteria. Only in this way can the effects of geometry (slenderness ratio) be isolated from the effects of the concomitant changes in the discretization schemes. By contrast, our formulation is largely free of such considerations.

We are indebted to $\mathrm{Mr}$ Wood for pointing out that the approximate analysis proposed by Poulos (1973) gives useful results for laterally loaded piles even for the non-homogeneous case $(\chi=0)$ despite the existence of a singularity (i.e. infinite displacements) at ground level. Later, Poulos (1978) showed that improved results could be obtained by symmetrizing the global pile-soil system equations by means of an empirical correction. Poulos (1979) has also presented a similar approximate method for the analysis of axially loaded piles.

Regarding the possible extension of the analysis to pile groups, we would like to point out that an analysis of the behaviour of laterally loaded pile groups embedded in non-homogeneous soils has been described by Banerjee (1977), Banerjee and Davies (1979) and Davies (1979) based on the present work on single piles. It has been found that such an analysis predicts realistic values for the interactions between individual piles in pile groups. These interactions are generally grossly overestimated by elastic analyses in which the soil is assumed to be homogeneous. An extension of the present analysis to include slipping and yielding of soils is also discussed in these publications.

An advanced computer program which implements these analyses is available free of cost to UK users from HECB Division, Department of Transport, London.

In conclusion, we are of the opinion that it is premature to suppose that a closed form solution (in the usual sense) exists for axially loaded piles embedded in non-homogeneous elastic soils. The 'closed form' solution, referred to by Mr Randolph in his discussion is, in fact, an exact solution of a much idealized representation of this complex problem: it is, nonetheless, an interesting contribution to this field of study.

\section{REFERENCES}

Amir, J. M. \& Rutenberg, A. (1974). Discussion on: Analysis of piles in soil undergoing lateral movement (H. G. Poulos). J. Am. Soc. Civ. Engrs 100, GT3; 375-376.

Banerjee, P. K. (1978). Analysis of axially and laterally loaded pile groups. Developments in soil mechanics (ed. Scott, C. R.). Applied Science Publishers, UK.

Banerjee, P. K. \& Davies, T. G. (1979). Analysis of some reported case histories of laterally loaded pile groups. Proc. Int. Conf. Num. Meth. Offshore Piling, London, The Institution of Civil Engineers, 83-90.

Davies, T. G. (1979). Linear and non-linear analyses of pile groups. PhD thesis, University of Wales, Cardiff.

Kuhlmeyer, R. L. (1979). Bending element for circular beams and piles. J. Am. Soc. Civ. Engrs 105, GT2, $325-330$.

Oteo, C. S. (1972). Discussion on: Behaviour of laterally loaded piles: II-Pile groups (H. G. Poulos). J. Am. Soc. Civ. Engrs 98, SM2, 226-231.

Poulos, H. G. (1973). Load-deflexion prediction for laterally loaded piles. Aust. Geomech. J. G3, No. 1, 1-8.

Poulos, H. G. (1978). Private communication.

Poulos, H. G. (1979). Settlement of single piles in nonhomogenous soil. J. Am. Soc. Civ. Engrs 105, GT5, $627-641$. 